\title{
Cross-Cultural Learning for Securing Decentralisation and Democratisation: \\ Assessing Indonesia's Response to Globalisation ${ }^{1}$
}

\author{
Purwo Santoso ${ }^{2}$ \\ Department of Politics and Government, \\ Universitas Gadjah Mada, Indonesia
}

\begin{abstract}
Drawn by globalization, Indonesia's governance has been transformed into a more decentralised and democratically shaped one in the past decade. Given the scale of the challenges, its achievement deserves admiration. Yet, the remaining challenges, namely to ensure that decentralised democratic governance remains culturally deep-seated in Indonesia politics is enormous. The stage of the transformation has hardly reached the fundamentally required cultural change due to the lack of cultural understanding within the process of transformation. Since democratisation and decentralisation are, essentially, forms of cultural engagement of global political-economic powers, the article proposes to reframe those two processes as the kings of cultural transformation. Analysing along this line of thought allows us to uncover the fact of the stubborn obstacle that Indonesia has been facing to reconcile the intangible, yet, continuously-embedded clashes of sub-cultures. A kind of cross-cultural learning strategy is important for Indonesia to secure that agenda.
\end{abstract}

1 Presented at the International Conference on Malay Culture and Society: Evaluating Malay Culture in the Era of Globalization Organized by Universiti Brunei Darussalam, Bandar Seri Begawan, 3-5 November 2009.

2 Purwo Santoso is a proffessor in political science at Department of Politics and Government, Faculty of Social and Political Sciences, Universitas Gadjah Mada, Indonesia 
Globalisation is an inevitable challenge to any country on this planet. ${ }^{3}$ It drives most countries into transforming themselves toward decentralised systems of democratic governance. In this regard, what really matters is not to agree or to disagree with globalisation, but how deal with it. ${ }^{4}$ While the importance of a vigilant response is well understood, a strategic response is not easy to make. In attempting to understand the difficulty in making an appropriate response to that issue, this paper offers a reflective overview with special reference to the cases of decentralisation and democratisation in Indonesia. At issue here is that while globalisation's role in bringing extensive exposure to externally induced processes of transformation is well understood, from my observation what is missing is an understanding of consolidated outward responses.

This paper relies on anecdotal observation in arguing that globalisation is mainly a cultural process, even though its political and economic dimensions are apparent. ${ }^{5}$ A cultural lens in analyzing how a particular country engages in the process of globalisation allows us to uncover the importance of learning processes - from which Indonesia may benefit. The first part of this paper establishes a claim that globalisation is a cultural encounter. Judging from Indonesia's response to globalisation it is clear that such a vision has not been adequately understood.

\section{Globalization as cross-cultural encounter}

It is hardly an exaggeration to say that globalisation is marked by engagements among world-class political and economic players in global scale arena. It has been embedded in the trajectory of human history, at least since the colonial era. The recent popularity of the term 'globalisation' in the current discourse should not in any

3 Manfred B. Steger; Globalism: The New Market Ideology, Rowman \& Littlefield Publisher Inc., 2002.

4 There has been controversy not only in understanding the nature of the problem but also how to go about it. The sceptics respond to globalization with a deep suspicion, while globalization-minded wing sought to have a well-thought strategy to deal with. It opens up new opportunity, but at the same time, exposes a particular country to risks. In the worst case scenario, globalization could drift a country in a chaos or despair.

5 Ibid., Chapter 2. 
way deny the fact that the very practices that characterise today's globalisation has been taking place for a long time. This process inevitably involves cultural encounters. Globalisation is a settlement of particular cultural practices through a series of instrumental changes. Through political and economic engagement, a certain cultural rearrangement takes place to the extent where a superior culture transforms the others. Globalisation, therefore, refers to a global-wide cultural transformation.

Global power secures their roles by ensuring the participating players share the same cultural lens. International norms are produced and discursive processes are at play to allow hegemonic practice to prevail in favour of the world-class players who hold worldwide leverage. In order to have strategic engagement in the increasingly globalised world, each country needs to have the courage to clearly and critically evaluate and then define its own cultural lens. Otherwise, countries merely serve the global interests that often play out internally while these countries often remain unaware of this prevailing hegemony.

In this context, it is fair to suggest that strategic responses and anticipation to globalisation should be culturally sensible to the given country where this process takes place. The problem then comes down to determining who are entitled to define which acts are culturally sensible and which are not. It is easy to say that each country is entitled to define what the sensible acts are and what are not. However, given the fact globalisation involves the reproduction of a certain social constructs any response to globalisation is going to be subject to a framing process undertaken by global players who have worldwide advantages. While it is desirable that each participating country be capable of defining what acts are deemed proper and what acts are not, it takes a great courage to ensure that frameworks which are globally set and nationally implemented are compatible to a particular cultural standard.

What sort of cultural arrangement does globalisation aim to settle? There is no doubt that globalisation carries liberal political ideas. Liberalism has provided the core values expressed in the application 
44 and reproduction of norms, institutional setups, procedures, and so forth, on the worldwide scale. This idea goes along with a modern culture that is competitive and rationalistic. In the light of this globally expressed liberalism, individuality is not only highly valued but is also meant to be the anchor of social order.

As globalisation becomes more intensive and deepens its penetration, the format of the state is shifting. Once understood and functioned as a 'collective self' representing the collectivity of its individual subjects, in many countries today the states have been losing its control over their individual subjects due to their relative effectiveness in expressing liberal order. Within this order, instead of being part of the collective self as represented by the state, individuals are instead encouraged to express themselves as autonomous agents capable of solving collective problems through voluntary exchanges, known to many as the market mechanism.

The liberally shaped cultural lens is highly suspicious of the state's potential abuse of power. Given the prevailing of liberalism in the ideological clash of the Cold War and its formation of a cultural lens, democracy has been commonly understood as a matter of constraining the potential abuse of policy makers or the rulers. Such constraint has been pursued through the so-called checks and balances mechanims, through which the civil society and other non-state actors are expected to be able to check state's power and authority. In this regard, the more the culture is effectively reshaped within the template of globalisation, the further the 'hollowing out' of the state proceeds.

It is important to bear in mind that globalisation takes place always in a specific country with its specific context and situation. It means that, unless a country is willing to share the cultural lens mentioned above, globalisation actually is not taking place in that particular country. In almost every country, there have many studies that have deemed globalisation as being a cultural threat. Yet, studies in international relations have confirmed that power has remained the key independent variable in shaping modern international relations. More specifically, globalisation has not radically changed 
fundamental aspects of international relations. It has merely altered the means and channels for exercising the power. ${ }^{6}$

As countries prepare to transform themselves aided with liberalcultural sensibility, a transnational process of transforming global governance is taking place. The outcome of such process, according to this line of thought, is that some sort of global consensus is resulting in the restructuring of the state. The liberal political culture is manifested in the advocacy of the growth of popular control in favour of preventing the state from abusing its power.

It is ironic that the globalisation process is currently hollowing the state since it was the very process that once prompted the establishment of the state - in the form that we know of today - across all parts of the globe. Developing countries, which mostly are post-colonial ones, inherited a particular form of polity known nowadays as the nation state through their colonial experiences. Colonialism shares various features, characteristics, and practices with present-day globalisation. The notion and practices of national state as a form of polity was transmitted from its birthplace in Europe to the other continents through colonialization process. However, the current development of globalisation has caused the state-centric mode of governance to lose its legitimacy in favour of its alternative - market-based governance. With regard to the notion of legitimacy, it is important to bear in mind that the distinction from legitimate to illegitimate action is from the view of a particular cultural lens.

A country makes a sensible respond to globalisation through a particular lens. The kind of response it makes depends on the cultural lens it uses to perceive its world. There is, therefore, a strong need to have a clear lens and a sound basis for engaging in the cultural encounter and coming to terms with globalisation. The absence of a cultural lens makes the response to globalisation arbitrary and unpredictable. The response might take different shapes, but those responds come out of particular cultural lens. Apparently, a country's ability to make a strategic response to globalisation — in this case

6 Sean Kay; "Globalization, Power, and Security”, Security Dialogue Vol. 35, No. 1, March 2004. 
46 democratisation and decentralisation - depends on the type of its cultural lens.

Globalisation affects each country by continuously reshaping the cultural lens it uses to perceive the world and its existence in it. Hypothetically, the reshaping process of values, norms, rules is no longer required when all those who participant within the global governance share exactly the same cultural lens. This might never come about in the real world. Nonetheless, looking at it in this way helps us to understand that it is the cultural lens in a given country that defines whether globalisation is to be successfully implemented in that country. The matching of cultural lens adopted worldwide with the lens adopted by a particular country allows the country to embark on the transformation process simply for the sake of global interest.

Globalisation essentially is a process to ensures that the national cultural lens is compatible with - if not exactly the same to the one used by other countries who serve as ideal models. For this reason, this paper will examine to what extent Indonesia has had a clear cultural lens for embarking on the massive reformation process in the aftermath of Suharto's presidency. Two tiers of transformation — namely democratisation and decentralisation — have taken place since then. The question is: 'What has driven the transformation?' To answer this, we need to find out whether it has been in response to internal problems in Indonesia, such as cultural diversity and the size of its territory etc, or to conform with the prevailing global governance. Or has Indonesia been dedicated to both of them. In other words, has the response to globalisation been a panic or a smart move?

What do previous findings tell us? Many things have undergone changes under the banner of globalisation. Yet, whether these changes receive public acceptance depends on how wider public affected by those changes respond to those changes. This process is basicaly political as indicated by the widespread of politics of culture that has been prevailing in all countries. ${ }^{7}$ Moreover, understanding

7 Kirk S. Kidwell; 'Politics, Performativity, Autopoiesis: Toward a Discourse 
globalisation as a politically critical cultural transformation is imperative. Encountering globalisation is essentially an experience in managing cultural change. It could be pro-active as well as reactive. To follow this argument, this paper treats democratisation and decentralisation - considered necessary in this globalised world as a cultural matter.

Democratisation and decentralisation are, among others, good examples of the changing character of means and channels being used by various actors in exercising their power. In the name of democracy and autonomy, new means and channels are introduced and shared all over the world, and these eventually reshape the global mode of governance. At this point, there is a double-edged cultural transformation. On the one hand, pre-disposition to particular style of democracy in each nation state leads to the formation of the so-called cosmopolitan democracy. ${ }^{8}$ On the other hand, the formation of context-specific models of democracy with the advance of global democracy continues to persist in each country, unless it unconditionally surrenders to the externally - imposed standards. ${ }^{9}$

In keeping global-wide governance in order, a governing principle is required. One among others is the concept of cosmopolitan democracy. Despite cosmopolitan democracy is being subject to severe criticism $^{10}$, it is important to note that it has relatively managed to establish hegemony. ${ }^{11}$ For example, in an attempt to adopt and adapt to the norms established within the banner of cosmopolitan democracy, globalisation eventually has managed to alter the way we understand democracy. We no longer treat it merely as a set of norms, but also an appropriate process dealing with public affairs. ${ }^{12}$ On the name of democracy each country engenders 'new

Systems Theory of Political Culture', in Studies $\$ Critical Methodologies, Volume 9 Number 4, August 2009 533-558.

8 Daniele Archibugi, 'Cosmopolitan Democracy and its Critics: A Review', in European Journal of International Relations 2004; 10; 437

9 Ibid.

10 Ibid.

11 Allen Chun, 'Globalization as Indigenization, or the Culture in Taiwanese National Politics', in Journal of Asian and African Studies, 2000; 35; 7

12 Daniele Archibugi,op. cit. 
48 social movements' engaged with issues that affect other individuals and communities, ${ }^{13}$ thus, engaging in globalisation, therefore, means allowing each nation state to undermine its own base of power. Democracy, within the mainstream interpretation of globalisation, “...erodes states' political autonomy and thereby curtails the efficacy of state-based democracy". ${ }^{14}$

The shifting conceptualisation of democracy - which is no longer state-based - renders the idea of decentralisation irrelevant. The discourse of decentralisation was once attached to the internal transformation within a state. As the increasingly globalised framework has become more prominent, the concept of decentralisation has also shifted. A new concept, namely decentralised governance, is on offer. ${ }^{15}$ Some significant ideas are conveyed in this concept: 1) the primacy of the cultural element, including in institutional arrangements to deal with public affairs at the local level; 2) no matter how local the arrangement might be, it is always suppossed to be directly in play with the dynamics of global governance. The mainstream interpretation is that the locals — be they state agencies, mass-based organisations or businesses - interact intensively in the international arena within the least possible constraint from the state.

Apparently, globalisation appears to be the transformation of the mode of governance upon which a market-based global political and economic order comes to play. As the state-based mode of governance is on the retreat and simultaneously the market-based mode is gaining prominence, the business-corporate entity enjoys more prominent and powerful role. In the name of cosmopolitan democracy, a set of cosmopolitan social standards are put in place. There has been a regime of truth in formation, along with its international legal instruments. Nonetheless, commonly acceptable form of accountability has been absence. ${ }^{16}$ Unreliability of global

13 Daniele Archibugi,op. cit.

14 Daniele Archibugi,op. cit.

15 G. Shabbir Cheema, Dennis A. Rondinelli (eds); Decentralizing Governance : Emerging Concepts and Practices, Ash Institute For Democratic Governance And InnovationHarvard University, Washington, 2007.

16 David Held, 'Globalization, Corporate Practice and Cosmopolitan Social Standards', in Contemporary Political Theory, 2002, 1, (59-78). 
economic accountability and social justice justify each nation in applying its own cultural lens in encountering the prevailing globalism.

The globally accepted idea of democracy is the one which is derived from liberal political philosophy. From a theoretical stand point, the term 'democracy' does not necessarily take the shape of the liberal form. ${ }^{17}$ Yet, given the hegemonic nature of discourse on this issue we are easily dragged into the predominantly liberal stream. Bearing this in mind, it is important to declare that this paper has no intention to neither deny nor advocate liberalism as the governing principle of globalisation. It treats liberalism as the setting of inevitable process of transformation a country needs. Nonetheless, for the sake of preparing the cultural ground to engage in a continuous learning process within the predominantly liberalised world, it is important to make some important propositions.

First, no matter what ideological standing a country wishes to take, good governance requires a strong cultural grounding that significantly contributes to the corresponding country's ability to express it consistently. Cultural transformation could take place through a process of interpretation and internalisation. By doing so, the existing cultural beliefs would be enriched and revitalised. A good example of cultural transformation through interpretation and internalisation was in the formation of Indonesian nationalism, given that previously the people of the 'Indonesian' archipelago had lived in small kingdoms, sultanates, or tribes prior to colonialisation. Failure to adapt in such a way would lead to cultural colonisation or subjugation, as it was for the people under the rule of a central colonial government in Batavia and, still further, Netherland. In the context of transforming a country into having democratic and decentralised governance, the country has to critically interpret and internalise things it deems culturally valuable. This is the point where understanding on how Indonesia understands democracy and

17 Stephen C. Angle, "Decent Democratic Centralism", Political Theory, Vol. 33 No. 4, August 2005 518-546. Se also Martin Leet; "Democracy and the Individual Deliberative and existential Negotiations"; Philosophy \& Social Criticism, vol. 29 no 6, pp. 681-702 
50 decentralisation is not only important but also interesting.

Second, the transformation through cultural learning requires a certain degree of confidence. Eagerness to learn from other cultures should be safeguarded by cultural awareness of its own. Overvaluing the predominantly liberalised mode of governance would show a fair indication toward a the lack of confident in its own culture. Such an overvaluation in an absence of cultural framework would potentially lead to adoption of an eclectic mode of governance. This might be desirable but would be deemed to be a failure if it had no means of reconciling contradictory demands. In this regard, it is noteworthy that uncritically engaging in transformation toward liberalism may lead to entrapment in various contradictions.

Third, liberal format of governance is very seductive. Yet, adopting such a format requires particular attitudes. That form of governance - manifest, for example, in the function of opposition-equips itself with capacity to engage in a continuous learning process. Expression of individual freedom (or liberty, rather) - the very foundation of liberalism — raises the chance of conflicts. Interestingly, liberalism has survived and even gained popularity due to its capability in managing conflicts. Moreover, the liberal format of governance equips itself with the capacity to learn by the way of transforming contradictions into dialectic. Progress through dialectic engagement, however, leaves serious potential shortcoming. Such engagement eventually, places the public into the hands of those who win the competition and potentially disregard those who lose or fail.

Four, learning cultural practices is beyond anyone's comprehension. This is because learning processes is inherent within the daily cultural engagement itself. Supposedly, the learning process should be thoroughly conducted by someone through research, and the problems to learn from and the lesson obtained should be deeply shared by the public. Otherwise, the learning process would end up merely with a report, instead of being geared toward the process of transformation. The tricky process of cultural learning is that people are normally attracted to appearance, including artefacts. Moreover, learning from the apparent appearance actually is the least important 
one. The most important — and also the most difficult — one is

learning cultural values. With regards to the topic of this paper, liberal values, which are the very much founded in the globalised mode of governance, are actually hidden beneath observable behaviours or activities.

\section{In trouble with globalisation: The absence of cultural sensitivity}

Democratisation and decentralisation are matters of state transformation in a culturally sensible way. Indeed, they are a matter of reshaping the prevailing power structure from time to time. Hence, democratisation and decentralisation involve a constant process of changes

The search for a suitable format of governance in Indonesia has been troubled by pragmatism. This is apparent from its unwillingness to learn from history and to analyze an issue from its cultural perspective. In fact, globalised discourse has gone unchallenged simply because following globalisation has been considered as following the most up-to-date trends. On the other hand, the prevailing global players have been struggling to actively set the global trend. Uncritical acceptance and adoption of the developing trend has tended to direct our focus on the question of 'What do we lack to fit the idealised ongoing trend?', instead "What are the underlying logic and power relations which have comprised the structure of the corresponding trend. Thus, it is hardly a surprise to see Indonesia as a country constantly more preoccupied with its internal affairs. This will be elaborated in the following sections.

\section{Unacquainted to the cultural ground of the state}

The basic format of governance in each country, including Indonesia, has been the idea of nation state. It is also known as the 'Westphalian' model of state. It emerged from European history, and then was actively propagated by European countries - colonial rulers - to other parts of the world. Through colonialism Europeans were able to apply the Westphalian mode of governance within their respective colonies. 
The application of this model has left numerous cultural problems, yet the idea of the Westphalian nation state has persisted throughout the histories of the post-colonised states. In this regard, the search for proper governance in Indonesia requires a certain degree of understanding about the legacy of Dutch colonial rule. The Westphalian model was invented to set a stable settlement among the conflicting powers in Europe in the $17^{\text {th }}$ Century. As the setting of the globalised world has changed, so too has the design of the state. In the recent wave of globalisation, the former colonial rulers have reshaped their own model of governance. They have changed from a better understanding that what they needed was not merely to end wars but, more importantly, to share collective progress through transnational cooperation. The consolidation that has occurred far has and been manifested in the institutionalisation of the European Union (EU). A prototype for a transnational state has been put in place.

This is not a historical study and, therefore, does not present engage itself with historical explanation here. Historical matters are briefly discussed merely to suggest that the current wave of globalisation must be understood in its connection with the unsettled implant of the idea of nation state. The Dutch coloniser had to engage in many encounters with various nationalities when it attempted to establish the Dutch East Indie. This project later on was taken over by the Indonesia nationalist movement, especially with the idea of nation state that is basically meant one state for each nation. Each nationality that comprises Indonesia has a particular cultural setup. The nation state of Indonesia is, essentially, transnational and, therefore, equivalent to the EU. Unlike the institutionalisation of EU, which is bottom-up in its character, institutionalisation of Indonesia has been otherwise. This fact leaves perennial deep-seated discontents rarely expressed. This paper will not outline the important lessons that can be drawn from this case.

Firstly, decentralisation is intended to pay respect to the cultural basis of each locality. This is contrary to the common understanding and practice of decentralisation in Indonesia, which proceeds with a top-down process. Nordholt and van Klinken (2007) mentioned 
that decentralisation in Indonesia has been basically understood

by the main actors involved, including International Monetary Fund and World Bank, as merely a financial administrative project. Confirming Hadiz, ${ }^{18}$ they argued that such a perspective blurred the other reality of struggle for power among various actors both at the national and local level. ${ }^{19}$

Secondly, decentralisation is a cultural affair in contrast to the prevailing discourse in Indonesia which treats decentralisation as an administrative -bureaucratic process. The failure to understand this unsettled nature of the nation state in Indonesia hypothetically links to the difficulty of the country to pursue the trajectory of globalised governance of - democratisation and decentralisation. Endless debates over democracy versus authoritarianism or a decentralised versus centralised format of governance have been taking place on the basis of a prevailing notion of the nation state. What does that mean? In thinking about appropriate formats of governance for Indonesia, we easily forget the following things:

1) The proper format of governance within the mind of the people is not necessarily consistent with the very idea of national state;

2) The Indonesian encounter with, and long-drawn-out usage of, the concept of nation state allows us to have a false impression that the only way to make Indonesia governable is through the development of a nation state. Moreover, if the very foundation of Indonesia as a nation state is found to be culturally ungrounded, the currently available framework for comprehending and conducting transformation is subject to reformulation.

3) There is a need to democratise and decentralise the mode of governance which, at the same time, would overcome the overdue process of mending the nation state. Apparently, there is no urgency to go back to the original design of nation state. The problems that are caused as a result, however, need to be

18 Hadiz, Vedi R. quoted in Nordholt, Henk Schulte and Gerry van Klinken. "Pendahulan" in Nordholt, Henk Schulte and Gerry van Klinken (eds.), 2007, Politik Lokal di Indonesia, Jakarta: KITLV and YOI, p.21

19 Ibid 
adequately addressed.

Related to Nordholt and van Klinken's statement mentioned above, academic analysis based on the technocratic perspective of governance in Indonesia has tended to take Indonesia as a nation state for granted, or at least no longer questioned it. The predominance of the legalistic-administrative understanding that has been well in place in the country since the declaration of the independence in 1945 has left small or no room for revisiting Indonesia as a nation state. The patriotic perspective, presupposing that the state was born through independence from colonial rule on 17 August, 1945, conceals an alternative understanding that, no matter how important the day of the declaration, the people's daily lives retain legacies from the past including their particular view of nation-hood. The patriotic proposition, denying any involvement of colonial rule in shaping the state, fails to recognise that the colonial framework is retained within the very practices of Indonesia as an independent modern state. Even the very idea of Indonesia as nation state was actually taken from colonial cultural politics by the activists of the independent movement. Through politics of language, namely facilitated by the Malay language (bahasa Melayu) as a lingua franca, was conducted by the Dutch colonial for uniting the country's vast diversity. ${ }^{20}$ Despite the denial by the patriotic lens, much of the colonial mode of governance, including the operation of modern bureaucracy, has been adopted by the later independent Indonesia. Culturally speaking, the legal birth date of the state does not necessarily mean immediate cultural rupture, either of the colonial or the traditional one.

At issue here is that the nation state of Indonesia is different from most nation states in Europe. In most European countries, the idea implies that one nation has one state - a state for each nationality. In the Indonesian context, there are at least two layers of nation. The first is the so-called civic-based nationalism. In this regard, nationalism refers to the existence of Indonesia as a collective imagination of

20 See Anderson, B.R.O.G, 2006, Imagined Communities: Reflection on the Origin and Spread of Nationalism, London: Verso, first published by Verso in 1983 
various ethnic groups, religious communities, or localities within the territory. Discourse of the nation state usually refers to this type of nationalism and, hence, we might call this 'national nationalism'. The crucial point here is to stress that even though this type of nationalism is all encompassing of ethnicity, religious affiliation and local identities, it is still in formation. The second layer of nationalism has a narrower scope, uniting the collective imaginations of each ethnic group, religious community, or local adherence. Nonetheless, this sort of nationalism is undoubtedly powerful and effective in consolidating collective or concerted actions. Moreover, even though national nationalism is attached to the state, the narrower type is capable to subvert the state. During the New Order period, this allowed for subversion which frustrated the regime. The pejorative term frequently used often by government official statements and in school class activities - of nasionalisme sempit — came to signify the power of society to challenge the state through cultural means. The new-born state of Indonesia was positioned on top of a fragile national nationalism in the sense that it remained potentially in conflict with other forms of nationalism.

It is important to note that awareness of the fragility of the structure of Indonesia as a nation state was deeply felt in the early post-independence era. This was evident in at least in two ways. Firstly, the founding fathers actively reproduced an old slogan, Bhinneka Tunggal Ika (Unity in Diversity), as the guiding principle for dealing with the issue of diversity. It signifies an imagined ideal of the Indonesia nation state, where on the one hand, it is expected to be able to establish itself as a nation-wide system while, at the same time, allowed for diversity to flourish among its subjects. The paradoxical situation was very clear in the minds of the founding fathers, although resolving this paradox has proved to be more difficult. This would explain why the slogan was incorporated into Indonesia's national Coat of Arms. Secondly, Sukarno, the first Indonesian president, embarked on what he himself called nation building. One of the important issues was overcoming issues of ethnic parochialism, which undeniably prevailed and, at some point, hindered the proper function of government. Local values and sentiments have continued 
56 to subvert Weberian rational-legalism, which the state's bureaucracy has officially aimed to ensure.

There are two issues of governance which need careful attention. Firstly, there is the problem in the relationship between statehood and nationhood. The inability to establish a synergetic relationship between the two, and to distinguish between them, leads to failure in governance. Nationwide statehood, which relies on the function of bureaucracy and technocracy, should seriously take into account the coexisting cultural practices of governance. Otherwise, the existing cultural practices might continuously present themselves as potential threat of subvertion for the operation of the state.

The second problem is the appearance of government. Governance processes take place both in the formal and informal domain. Beneath the formality of the process lays a dense and complex network operating according to the cultural norms in place. For proper or appropriate governance, Indonesia inevitably has to deal with these two issues. Our search for proper or appropriate governance would be loosely grounded, if culturally uprooted, unless these two issues were well incorporated. This, unfortunately, has not been the case.

Indonesia has been understood as a 'weak state' and has ranked within the category of 'warning' in the Failed State Index 2012. ${ }^{21}$ This is ironic because it is endowed with cultural power concentrated on various cultural entities. The state has been uneasy - not to say unable - in disciplining itself. The state consistently faces difficulties in implementing its own policies given the inconsistency of its normative grounds to govern. For example, citizenship is often in conflict with kinship. Normatively, the state is responsible for serving the public on the basis of citizenship. This is grounded on the idea of civic nationalism. However, in practice it is difficult for the agents of the state bureaucracy to live up to this principle of modern state. This is their multiple positions as subject. Besides as state bureaucrats, many of them also belong to certain sub-national

21 Failed State Index 2012, The Fund for Peacehttp://www.fundforpeace.org/ global/?q=fsi-grid2012, Saturday, June 31, 2012, 11.22pm 
social formation based on different kinds of membership, including kinship. In their day to day activities as state's bureaucrats, they often face dilemmatic situation of divided loyalties. In the one hand, as state's bureaucrats they are required to treat every citizen equally regardless their cultural and kinship backgrounds. As member of their respective kinship groups, however, they are obliged to favor their fellow kinship members or they might face social punishment from their respective communities. In this situation, the commonly solution taken by bureaucrats is to give priority to relatives and hide the evidence of discriminative practice administratively.

The point here is not merely that the state apparatus weakens the state itself for cultural reasons, but to show that the capacity of cultural power to keep the state in check. Interestingly, the power has been at play silently - even beyond the country's experts in the field of governance studies. This is the basis for setting up modes of governance in Indonesia and, hence, explains why democracy and decentralisation remain problematic issues. There is good reason to suspect that the problem is rooted due to the absence of the cultural dimension within the studies and discourses on democratisation and decentralisation. The following section attempts to probe this matter by reviewing the discourse.

The most important practice is in making an appropriate category. This paper has introduced various ways of devising categories: statehood versus nationhood; formal versus informal governance; strong versus weak state, etc. The failure to make a clear and consistent category indicates the lack of mastery in responding to external challenges and pressure. Other countries or players easily control weaker countries by imposing their own category labels. Evaluating through this yardstick raises a deep concern. Public discourses are easily trapped into categories that are not culturally grounded.

Discourse on democracy and decentralisation in Indonesia has been naïve in assuming that Indonesia as a nation state is no longer affected by inherited cultural problems that prevent it from 
58 performing well. ${ }^{22}$ As mentioned earlier, nation building in this country is an unfinished agenda. Unless the public shares a strong sense of urgency to do so, Indonesia is actually committed to globalisation in a reversed way. It leaves to global forces - which have been penetrating the country through the prevailing discursive engagement — to decide on the direction Indonesia should take. The nation state has been transforming itself in adapting to the globalised world. What Indonesia fails to do is to identify solid and well-placed stepping stones to ease the future challenges of globalisation.

To my observation, the cultural context has not been well thought out, especially among political scientists in this country. This has resulted in the stepping stones being unreliable. The community of Indonesian intellectuals have rarely, if ever, made use of a cultural lens in their analysis and, hence, have failed to prevent cultural imperialism. Despite being such an enlightened section of society, it is basically unaware of the hidden practice known as 'academic imperialism', 'orientalism' or 'euro centrism', and fails to connect its own cultural basis with the globalising world.

Believing that public discourse potentially frames social practice, the absence of a cultural lens allows democratisation and decentralisation to occur at odds with cultural practices. This leads to two simultaneous situations. Firstly, the discourse and the practice fail to grasp the problems. Secondly, it overstates the perceived success. These problems are the subjects of the following section.

\section{Not framing but framed by global crisis}

Democratisation and decentralization in post-Suharto Indonesia seems to be misplaced since it has been grounded on false assumptions. This leads to the failure to grasp the discrepancies of the implementation of those two processes as discursive practice. This situation is indicated one among other is by the persistency of many jargons produced and used during the era of Soekarno's Guided Democracy that are still in use today, mostly as ungrounded assumptions. For example, though the fact that the current mode of

22 Nordholt and van Klinken, op.cit 
governance was not satisfactory, there has been eagerness to relate

it with its basis, namely nation state understood as an integralistic entity. This particular view of the state perceives the multiple and diverse ethnic, religious, and cultural groups as reminisence of historical past that has transformed themselves and should transform themselves as merely passive elements of the new and broader entity of Indonesia nation represented by the state at the center. Such view neglects the fact that these particular groups retain their particular point of view and way of life as particular entities. The persistency to initiate democratization and decentralization based on the assumptions mentioned in the previous paragraph leads to the situation where there is overstatement of the capacity of the nation state. This takes place simultaneously with the use of formalistic lens through which informal governance is missed out despite its strength in cultural sense.

The second situation that put Indonesia's cultural grounds in engaging with the globalised order into a test is its ability to identify and respond to discursive power that is concealed beneath the practices of daily life. The country had not been able to settle fundamental issues beneath the surface of democratisation and decentralisation. This explains why democratisation and decentralisation has periodically appeared in the contemporary history of Indonesia. Radical changes have been taken at certain points, but on these occasions the formation of new consensus in response has determined that the direction taken was wrong. The consequence of this is apparent - namely, repeated returns to the beginning. This would indicate that something very fundamental has been falsely addressed.

In terms of democratisation, there was pressure and even attempts to adopt liberal democracy not long after independence. The legacy of the attempt is referred to as era demokrasi liberal (liberal democracy era). This term was used in derogatory sense during the eras of Soekarno's Guided Democracy and Suharto's authoritarian era to discredit the choice or adherence to a liberal institutional design. Interestingly, since the authoritarian rule of Suharto broke down, the country has returned to the former liberal democratic setup. Similarly to previous liberal periods in the 1950 s, the post- 
60 New Order era of liberal democracy has also been one for launching decentralisation on a massive scale.

The fact that the issues have appeared, disappeared, and then reappeared would indicate that Indonesia has not been able to culturally settle and resolve them. At issue here is not necessarily the rejection to the ideas of democracy or autonomy derived from decentralisation, but concerns on the institutional arrangement and ability to convey these ideas in the real context - which is certainly a diverse and constantly changing one. This paper has no interest in defending authoritarianism. Democratisation was brought about as if it was like computer software being installed. The elites who promote democracy, precisely liberal democracy, imagine that democratisation is a matter of introducing sets of organisation and procedural arrangements. They practically do not bother to check whether the public thinks and acts according to the liberal mindset. The miss-match between the institutional or procedural setup and the mindset of the public leaves democratic practice as ambivalent.

Given the fact that the state has been weak, discourse on decentralisation turns out to be misleading. Why? Whether the authority of the state is decentralised, locals have been able to find their own way to manage their problems. Locals have various way of hijacking the state's power. Culturally speaking, locals have not been desperate for local power as it is commonly thought. The public in Indonesia is consolidated along cultural and religious affiliations, and to some extent these are self-governing. Whether the state decentralises its mode of governance, there is a self-governing capacity in practice which is difficult for the state to ignore. The problem, which is apparently taken seriously from the legalisticadministrative point of view, is that the governing process takes place within an informal domain, relying on informal actors. In essence, decentralisation is a willingness to acknowledge the fact that the prevailing mode of informal governance is a legitimate practice.

The reluctance to acknowledge the existence and functioning of culturally-rooted and locally-based modes of governance gives a false impression that decentralisation has caused problems at the local 
level. Indeed, local power works in accordance with its own logic 61 and its own interpretation of what is the proper thing to do. In this respect, decentralisation should be perceived as a reliance on local power in dealing with public affairs. This is what decentralisation is all about. It becomes a problem-creating policy because it is seen from the perspective of those who have been accustomed to centralised mode of governance. Essentially, these figures are uneasy in dealing with diversity, and unable to see things from the local perspective.

The global financial crisis in East Asia and Southeast Asia during the mid 1990s resulted in the economic crisis and then political crisis in Indonesia. This crisis undermined the legitimacy in the institutional design of the authoritarian New Order state. Deep crisis, as policy studies have recognised, provides wide opportunity to embark on radical change. This was the case in terms of democratisation and decentralisation. From that point on, much legislation has been produced with the aim of liberalise the country's political and economic structures. Such legislation has come to regulate previously sensitive issues including elections, political parties, local government, the press, and so on. In the wake of enthusiastic changes, constitutional change also took place to legally signify them.

\section{Democratisation and decentralisation: Loosely grounded reform}

Unlike Europeans who have consolidated their existing states under the broader banner of the EU, Indonesia has done the reverse. As the country has returned to the framework of liberal democracy, simultaneous with the initiation of decentralization policy, there has also been strong demands from the locals to have their own autonomous local governments. Thus, the number of local governments has almost doubled within only a decade. This has been a manifestation of an inward-looking cultural lens.

In order to see the cultural lens employed in the country, there are two important things to note. First, the process faced is understood as a domestic process which rather neglects the contribution of global financial governance. The predominant discourse which unites public debate gives the impression that the main problem was 
62 Suharto, who was morally wrong in choosing authoritarianism and a centralistic mode of governance. The perspective that sees marketbased governance - as the thrust behind globalised governance as the primary force that led this country into serious turbulence, has never risen to the surface. This could be called as public blindness - something taken advantage of by a number of politically motivated actors.

The second noteworthy thing is that a deep hatred toward Suharto has provided strong confidence in the combined effort for democratisation and decentralisation project as the only way to go. Moreover, this enthusiasm has left behind a strong impression that whatever asassociated with Suharto was bad, even though in reality people could not easily disassociate themselves from it.

Within the light of this changing discourse, democratisation and decentralisation sit as among the most important issues for Indonesia. Since a proper response to globalisation requires a strong local basis and, at the same time, aims to have a strategic role in the global arena, the prevailing legal and institutional arrangement should be subject to investigation. Reading the Act on decentralisation and local governance would provide us with some basis to uncover the cultural lens taken by Indonesia.

\section{Central-local relationship}

The first post-Suharto law specifically designed to push for decentralised democracy was the Act No. 22 of 1999. This law was officially implemented in 2000. This Act set Indonesia on the path to radical change in that central government was treated like a federal government, rendered to being responsible for issues common to federal authorities - for example, defense, foreign policy, and the judiciary. The Act officially declared that most of the state's authority would be redistributed to regency or municipal governments. To protect this arrangement, the Act also determined that provincial governments were different sets of local government. It became no longer the place or chanell through which the regencies of municipalities take instruction from the central government.

An observation from this change is that consciousness of 
Indonesia's diversity has made the Act implicitly adopt federalism.

This was a brave attempt given that the perception of federalism as something divisive against national unity was still strong in Indonesian public's opinion and an institutional framework to unite the country did not exist. While federalism has offered a framework to govern cultural diversity, it has not adequately addressed the 'uniting' factor. It could be argued that the Act was not well thought through. Inter-regional discrepancies, such as the different levels of economic development and the absence of infrastructure in some remote parts of the country, were not taken into account. It turned out that despite the broad autonomy given to the local government under this act the west-edge and the east-edge parts of the country retained their discontent, and continued in struggling for different treatment. Later on, these two provinces managed to obtain special arrangement. Special autonomy laws for Papua and, some time later, for Aceh were enacted. What does this tell us?

Firstly, federalism, which has been a readily available framework implemented elsewhere in the world, was inssufficient either. Careful and prolonged negotiations which took place one by one apparently consolidated a new understanding, then known as asymmetric decentralisation. Decentralisation was initially — and still officially — understood as a single design applicable for all. Moreover, it is perceived toproceed from the 'top' level to the 'bottom' (top-down). Within this framework of decentralization, apparently, it would be less likely to work through negotiation and to seriously take into account the differences. Unfortunately, the experiences of the regions like Aceh and Papua that manage to negotiate their terms for special arrangement might tell other regions that for negotiation to take place between the central government and the locals, armed movement is necessary.

Second, transferring the state's authority from the Jakartabased central government to each regency and municipality was a sympathetic idea for Indonesia. What was missing was an appropriate process for carrying it out. The Act did not provide any idea on how to achieve such a wonderful idea. Moreover, the imagination that decentralisation was a matter of transferring authority was deceiving. 
64 From field observations, it would seem that the primary concern has not so much been about the attribution of authority to the local level, but how to make the authority function in order to serve the public. In other words, the trouble in decentralising governance was to match formal authority with informal types which already existed. The mismatch between formal and informal authority has potentially to underperformance - if not dysfunction - in local governance. Obviously, pretending that informal authority was not previously in existence, and pretending that the administrative approach as was the only process that takes place place, would not only be deceiving but also potentially disastrous for decentralisation and democratisation.

\section{Empowering local legislature}

The other point set out by the Act was that the local legislature became no longer part of local government. Instead, it became very powerful in its own right, and this change happened in a sudden. This was the institution to whom the heads of local government (Regents, Majors or Governors) were held accountable for their policies and decisions. An important observation on this particular issue would be that the expectation that the local-level legislatures would be instantly empowered and work positively for democratizing local governance just simply because the Act said so, was awfully naïve. Unfortunately, that was not the case in majority local governments in Indonesia. With the huge power in its hand to elect or depose a head of local governement, the local parliament turned itself into another actor in the intricate web of power brokery, involving practices such as money politics, extortion, fraud, and many others. Instead of reducing the extent and degree of dirty political practices previously associated with Soeharto's New Order, the empowerment of local legislature through this act rather extensified the scope and intensified the degree of those practices.

\section{Overstate Superficial Achievement.}

To counter balance the critical account on what has occurred, it is important to point out to the fact that Indonesia has been enjoying international recognition for its ability to sustain the 'big- 
bang model' of democratisation in tandem with decentralisation.

Judgment on the success on this matter, however, has been based on superficial aspects. Success in democratisation has been, in this regard, been oversimplified by success in conducting general elections with tolerable degrees of violence. Success in decentralisation has, too, been oversimplified by the formal or legal processes of delegating an extensive amount of national authority to the local level. These perceived successes have concealed the insights that success in general elections had not led to democratic policy - making and that legal attribution to local authorities retained deep-seated conflict between national authorities and local counterparts.

As earlier sections of this article have demonstrated how the processes of democratisation and decentralisation in Indonesia have been moving back and forth for decades The changes that have taken place extensively during the post-Suharto era have created the slippery impression that Indonesia has undergone a fundamental process of democratisation and decentralisation.

The very foundation of Indonesia as a nation state made up of many culturally diverse nations has not been settled. Yet, it would see that the country has undergone liberalisation - which could essentially be considered as a transformation of the state itself. In a way, the liberally inspired transformation in Indonesia was inevitably triggered by the re-emergence of unsettled issues such as the ethnicity, secular vs. Islamic state, etc.

Cultural problems in bringing about those ideas stemmed from the fact that they were heavily loaded with contradicting values to settle. Moreover, the country has not been able to settle its foundation to govern the complexity within it. The process of nation building which President Sukarno started a long time ago was terminated involuntarily. That agenda fell down while President Suharto led the country. In the aftermath of Suharto's presidency, the country was still unable to deal with the paramount problem in devising institutional devises to govern such a vast territory and cultural diversity. The cyclical appearance of issue of democratisation and decentralisation could be seen as being rooted in the inability 
66 to solve the necessity paradox inherent in the nation's cornerstone philosophy which has been passed down by the founder fathers namely, to respect diversity at the same time as relying on a united system. In governing the country, Suharto gave heavy emphasis to unity due to his worries about the diversity he encountered. The current style of governance has overemphasised the diversity aspect, while having been troubled with maintaining unity.

The re-emergence of the issues of democratisation and decentralisation was triggered by the economic and political crises which forced President Suharto to step down. The crumble of legitimacy based on centralised rules during the crisis allowed for the enactment of a radical reform agenda. This was headlined by the political reformists' success in achieving the enactment of Act No. 22 of 1999 on Local Government. Despite the mounting euphoria at that time, this Act aimed to simply reverse the mode of governance institutionalised during more than three decade of Suharto presidency. It was dedicated to bringing about a radical political transformation through the dismantling of the previously centralistic form of governance and introduction of decentralised governance based on a liberal democratic setup.

\section{Securing the process: Cross-cultural learning}

The aforementioned description showed how democratisation and decentralisation has been treated merely as bureaucratic and technocratic matters. Moreover, a mere bureau-technocratic approach toward democracy and decentralisation was insufficient. The preponderance of that approach to duplicate the same mistake of neglecting and overlooking the cultural dimensions of Indonesian society was never very likely to bring us forward.

The bureaucratic-technocratic approach placed the value of effectiveness and efficiency of democratisation and decentralisation as the main virtue. Translated into mere rules and procedures made by the experts among the state bureaucracy and universities, however, these rules and procedures have, in most cases, been found incompatible with the context and situation of where it has be 
applied. ${ }^{23}$ It has been mostly due to the assumption that these rules and procedures would be surely compatible and applicable for all situations and contexts.

This assumption, somehow, is an exaggeration and is a mistake that is repeatedly committed by the central government. It is a mistake because it is widely known and accepted that Indonesia is constituted by so many diverse groups and identities which overlap and cut across the different types of membership in society. Whether this fact, however, serves us, as an advantage or disadvantage for achieving our goal, depends on the perspective we use to see it. The dominant formalistic and legalistic perspective tends to see Indonesian diversity as a problem, or at least a barrier, in building a unified Indonesia.

We may see this as an inherent and logical consequence of the dominant bureaucratic-technocratic approach which views 'politics' and 'the muddling through' process of participation and deliberation as something at odds with the goals of effectiveness and efficiency. In this positivistic approach, politics should be reduced into merely technical and expertise matters. ${ }^{24}$ Thus, on the one hand, the currently dominant bureaucratic-technocratic perspective used in dealing with democratisation and decentralisation poses, somehow, a threat toward these very processes. On the other hand, it is acknowledged that the future of democratisation and decentralisation also depends on bureaucratic and technocratic arrangements and expertise.

23 Pratikno et.al. (eds.) 2004, Perjuangan Menuju Puncak: Perjuangan Menuju Puncak Kajian Akademis Pembentukan Kabupaten Puncak - Pemekaran Kabupaten Puncak Jaya Provinsi Papua, PLOD UGM and Regency Government of Puncak Jaya, Chapters one and two show good cases for how the procedures and rules for democratisation and decentralisation, specifically in the Formation of New Autonomous Region Policy, were found to be incompatible in some areas in Indonesia. The analysis in that book stated that to merely view and judge the policy through the lens of formal procedures and rules has made the government prone to overlooking the contextual needs and cultural dimension for the decentralisation policy, especially in presenting itself, in the form of public service, before the Indonesian people and citizens who live in remote isolated and border areas. In turn, this will bring consequences both for the citizens, having their rights for public service provided by the state denied, and for the state, the perennial threat of separatism in some areas of Indonesia.

24 See also Fischer, Frank (1990) Technocracy and the Politics of Expertise, in Sage Publications: Calif. pp. 15-17. 
The cultural perspective serves as an alternative for examining democracy and decentralisation in Indonesia, besides the conventional bureaucratic and formalistic perspectives. Through this perspective, various parties are encouraged to actively participate in the process of learning through intensive cultural encounters. It does not necessarily exclude the existing formal institutional and organisational arrangement; in fact, the encounter and learning processes are built based on and managed through the existing formal institutional arrangements.

Indonesian government and society needs to make a thorough reflection and evaluation on what they have achieved so far. It is imperative to make sure that the involved parties are themselves participating in these processes of cultural encounters and learning with the logic of accumulation, instead of distribution, in their mind. By keeping this logic in mind, the continuation of the unfinished process of Indonesian national building will be possible. Consequently, the decision to adopt this logical framework of accumulation should be complemented with the primacy of collective identity alongside the particular ones of religion, ethnicity, language, and culture.

The cultural encounters serve as a fora for various particular identities among Indonesian society to directly meet each other and get to know each other. Only from such an encounter it becomes possible for a multitude of Indonesians to continuously negotiate and build genuine understanding. It departs from the understanding that each particular identity should constitute the imagined communities of Indonesia. These particular identities are something with their own lives that have a living energy to act, react, and adapt to the environment they encounter, including other identities. Thus, genuine understanding should also incorporate understanding the dynamic potentials of these entities, instead of merely treating like some sort of relics from the past time displayed in a museum. ${ }^{25} \mathrm{It}$

25 A major example of how the New Order regime treated Indonesian diversity was in the most notorious project of Taman Mini Indonesia Indah. For further explanation of how this project was designed to treat Indonesia's diverse identities as mere lifeless relics, see Dhakidae, Daniel (2007) Cendekiawan dan Kekuasaan di Masa Orde Baru, Gramedia: Jakarta. 
is also noteworthy that most of these particular identities have been existed long before the establihment of Indonesia nation state, even before the coming of colonial powers.

Many of these centuries particular identities which comprise the Indonesian identity have engaged and established themselves among other cultural entities worldwide. Through sea trade networks these identities and other encountered cultural entities, learning how to build shared understanding and also adapting themselves both to the other entities which they encountered but to also the changing environment. Lombard's work of Nusa Jawa Silang Budaya and Reid's The Lands Below the Winds have showed that various cultural entities in the islands of Nusantara have been long connected through various encounters, and each has been able to draw some lessons through these encounters. ${ }^{26}$ Since each of these cultural entities has drawn their own lessons and developed their own paths to adapt, it is not surprising if the effort to unify them has becomes laborious and without a proper approach, and hazardous with ethnic and religious conflicts since the fall of the New Order regime.

Thus, it is necessary to give room and allow more opportunity for these diverse cultural entities and particular identities to express themselves in order to build genuine understanding. This is possible only if we are able to facilitate more encounters among these cultural entities and particular identities. Genuine encounters are not abstract discussions that occur in the court or meeting rooms at the parliament building, but the simple matters of everyday life. Another no-less-important task in facilitating these cultural encounters is to ensure they are manageable and lead to the desired goals. At this point collective identity plays a crucial role.

26 Lombard's work shows the case of Java and Javanese societies as a site and actor of this cultural engagement and learning, resulted Java and its societies as a cultural intersection, where the influence of various cultures gave color to what now known as Javanese culture. In this case, the Javanese still holds the control of what is considered appropriate and what is not from these strange cultures. They, however, acknowledge that such encounter is inevitable thus they adapt themselves to adapt as well to manage the occurred encounters and the influence coming from them. See, Lombar, Denys (2000) Nusa Jawa Silang Budaya, Vol 1, 2, 3; Winarsih P.A. et.al transl., P.T. Gramedia Pustaka Utama: Jakarta; first published 1996. 
The collective identity serves to bind together the wide diversity of Indonesian society. Previously, the common goals of gaining political freedom from Dutch colonial rule - though controversial - served as the main base of this collective identity. Post-independence development, however, has grown into situation in which the common goal has come into question, especially when considering the discrepancies between Java and outer-Java. The grim precedent of the imposition of a collective identity through modern development goals under the New Order regime which, unfortunately, were pursued more through coercive means, has embittered some Indonesians, especially those who live in Aceh, Papua, and several others regions with long histories of separatism. Their response toward collective identity has been mostly sceptical, for not to say totally distrustful.

The New Order regime treated the diverse nature of Indonesian society mainly through manipulation, serving the dual goals of binding them in the chain of dependency to the central government at Jakarta and making them easy targets for political mobilisation to ensure the regime's continued rule. Through such a policy, the previous regime produced a monopolar form of governance centred on Jakarta. ${ }^{27}$ Every idea about creating another centre was considered an act of disobedience or, worst, separatism, warranting an iron-fisted response from the centre.

The demise of central government control after the fall of New Order regime witnessed the flourishing of long-oppressed expression from various particular identities and cultural entities, seeking to claim their rights. Unfortunately, in expressing their demands each these identities and cultural entities tended to target symbols which once represented the privileged ones during the New Order era. In most instances of conflict which escalated into violence, these symbols were attributed toward other particular identities or cultural entities. This phenomenon was mostly due to the previous New Order policy

27 This pattern of mono-polarity is clearly seen in the flight route of almost all Indonesian major flight company. To reach one place, even one on the same island, people have to take the long route to Jakarta first, and then take another flight to the intended destination. 
that focused on developing interaction and engagement between the groups and the central government instead of among themselves. Alongside the discriminative policy of the ruling regime which gave privilege to certain particular identities and cultural identities at the expense of other, the lack of communication, encounters, and understanding among these groups have created prejudice and stereotypes among them. Because of the lack of communication and encounters among members of each these group, such prejudice and stereotyping was accepted as being truthful and served as basis for group in referring to other.

As mentioned before, in order to reverse this negative effect, it has been imperative to open wider room for engagement among these particular identities and cultural entities, framed in a collective identity of being Indonesian. This common identity must be based on a more relevant and commonly shared purpose and direction which would be available through the involvement of these particular identities and cultural entities in the bigger framework of Indonesia.

Only after these pre-requirements of reflections, cultural engagement and collective identity have been met we may begin to build Indonesia in through a multipolar framework. This framework would place various overlapping and cross-cutting identities, constituted as the Indonesian identity, in a process of intensive mutual learning in order to build mutual understanding among the groups. To be cautious, it would be necessary to state in the first instance that this process required audacity, determination, as well as much heart from all the involved parties to keep work on this long quest for lasting mutual understanding among them. The logical fallacy of distribution and the impassionate response toward the accumulation process has resulted in the rocketing number of new autonomous regions in Indonesia within the past decade. Worse of all, the problems of logical fallacy and impassionate response from the particular elements of Indonesia go alongside the central government's failure in wealth distribution.

I acknowledge that such a multipolar mode of governance based on a accumulative logical framework would only be possible in 
72 Indonesian context if strong leadership provided a strong vision for going forward. This vision, however, must be structurally shared and institutionalised and it must be done through a consensual process among particular identities and cultural entities which constitute Indonesia. One of the main roles of the leader here would be to facilitate the cultural encounters that make possible understanding and consensus building among these diverse groups.

Physical infrastructure would be most needed to allow for such cultural encounters to take place. The central government, for now, would be the only party who has the ability required for developing physical infrastructure to connect various parts of Indonesia, since such a project would require much planning capacity. Thus, the leader at the central government should make maximum contribution by gives their best on this task. ${ }^{28}$

Among the particular identities and cultural entities within society, such a vision and opportunity should be responded by developing their own institutional learning capacities. If during the previous regime they were demanded to merely obey, now each would be required to develop their capacity to learn, articulate, and negotiate their interests with other particular groups and the central government.

In developing this organisational learning capacity, each particular group would need to, firstly, make a self-evaluation on what they have done so far and what they would do in the future. Through the cultural engagement this self-evaluation would be shared and communicated with other groups. The willingness to share and communicate would be crucial here, since only through this would it be possible for those groups to build a mutual understanding which could be transformed into further cooperation and inter-linkages.

The government at every level should develop the same capacity and involve itself in the cultural engagement process. On the part of government, the organisational learning capacity could be translated

28 At the provincial and local levels leadership at the Province of Kalimantan Tengah could be made as a good example. See 50 Tahun Kalimantan Tengah, Postgraduate Program for Political Science, Local Politics and Regional Autonomy, 2007. 
as the maximisation of research and developments (R\&D) function within its structure. The government organisation running this function should become a reference in the policy-making process.

Also important in such a process would be for each party to avoid the technocratic and positivistic traps. As mentioned earlier, the mistake previously made was in overlooking the cultural dimension of Indonesian society and its diversity, and was due to the reduction of Indonesian political and social phenomena into mere calculations of effectiveness and efficiency. In this cultural perspective, the historical path becomes one of the determining factors for what would happen in the future.

In this process of self-reflection and evaluation, and communication with other parties, inevitably there must be some things that would be unpleasant or share with others. The parties involved, however, should deal with such cases with open mindedness - truth, however bitter, would always be better than falsity. Indonesian historiography could serve as a good example. As recently revealed, Indonesian history has had many missing links which need thorough research in order to gain a clearer picture. This has been partly due to the previous regime's policy of manipulating history to legitimise its rule. This manipulated history has been reproduced over the span of decades, and has been deeply rooted in the mind of most Indonesian and accepted as nearly undeniable truth. People's understanding of history gives influence to how he/she understands and responds to their current situation. If one responds to his current situation based on a manipulated history, inevitably they would be prone to arriving at the wrong decision that could lead to unintended consequences. One first important step toward gaining clearer view of our history would be through opening up 'the other stories' to reveal the truth other those that have been imposed.

In managing the diversity of Indonesian society through this cultural perspective, the state should not co-opt various entities, including religious organisations. Instead, the state should facilitate the engagement among these entities, and more than merely through a consociational model of representation. The state should also 
74 through provide them with a channel for direct encounters, making it possible for them to know each other better and to take on board the lessons of such encounters.

In the governance context, this organisational learning capacity should at least include two components - political learning and policy learning. Policy learning itself includes the so-called instrumental learning and social learning. ${ }^{29}$ Political learning capacity would provide the involved parties the tools to understand the contextual dimension of their existence and then relate their ideas with the existing context. This capacity would help them to determine their strategy in order to promote their ideas or respond to the policy problems they encountered. For the various groups within society this capacity would be useful in articulating and promoting their ideas in the agenda-setting process. For the government, this capacity would serve in guiding it to formulate the relevant policies to frame the diversity of Indonesian society in a unifying and more democratic manner.

Policy learning would consist of two components - the social learning capacity and instrumental learning capacity. Social learning capacity is related to the ability to understand the social construction of any given policy. It would give the involved parties sensitivity toward the values and norms pursued through any given policy. Instrumental learning capacity would give the involved parties more options and alternatives on possible measures of policy intervention or implementation designs.

The case of Yogyakarta, which has succeeded in maintaining its status as the capital for Javanese culture and, at the same time, the weaver of unity for Indonesia, could be seen as a best practice case. The city's political learning capacity has enabled her to see and understand the political propensity which favoured the establishment of a nation state. In order to maintain its existence in this new situation, the correct response has been forthcoming from the old institution of the Sultanate. Instead of simply being a spectator in the establishment

29 May, Peter J., Policy Learning and Failure; Journal of Public Policy part 4, 1992, pp. 331-354. 
and institutionalisation of the nation state, the Sultanate under the 75 visionary leadership of Sultan Hamengkubuwono IX has played an active role in the process since the very beginning. Firstly, during harsh times the Sultan offered Yogyakarta as the capital city of the newly born republic even though this meant putting the city at risk of becoming a military target of the returning Dutch forces. This decision proved the Sultanate's commitment toward the establishment of the new Republic of Indonesia, and toward its ongoing existence.

Secondly, considering the inevitable interaction with modernity, the Sultanate quickly responded by handing over some of his estate for the establishment of the first university of the independent Indonesia - Gadjah Mada University. Through this university, the Sultanate has played the role as one of the main weavers of Indonesian unity. Students of this university come from all over Indonesia, brining their own cultures, customs, languages, values, and norms. As a result, Yogyakarta has been dubbed 'Indonesia Mini'. In contrast to the Taman Mini Indonesia Indah park in Jakarta, the 'Indonesia Mini' has positive associations because of the respect for diversity — in its living form in - Yogyakarta. In this continued peaceful interaction, there must be moments where each participant has to learn about each other and, from there, they build mutual understandings. The beautiful diversity and harmonious interactions and relationships among various particular identities and cultural entities in Yogyakarta are the paramount of the continuous effort of cultural learning through daily cultural encounters of its participants.

The case of Yogyakarta is an example of successful cultural encounters and learning. The process produces a sense of pride toward Indonesia's cultural diversity, without the impostion of neglect toward the particular identities of each participant. Thus, my particular identity as Muslim or Christian or Javanese or Papuan does not stand against my identity as an Indonesian. Instead, my identity as an Indonesian enables me to express my particular identities stronger because each of them is one of parts that constitute the Indonesian identity.

The explanation above deals with how the cultural encounter 
76 and learning are carried and institutionalised at the society level, and mostly through informal channels. For this scheme to work, a parallel effort must be made at the governmental level, in its broad sense, and through formal channels. The Regional Representative Council (Dewan Perwakilan Daerah, DPD) could serve the cause of weaving Indonesian unity through its diversity.

As we know, the DPD is a national body in which most of its members come from across Indonesia. Their function is to represent regional and local interests at the national level. In order to maximise the DPD's function, it would be necessary to facilitate this body and its members to be better-rooted with its constituents at the local level and in maintaining engagement with members representing other localities. Through this there would be a well-connected chain of representation in which the populace from various localities would have access to the policy-making process at national level. This formal channel would help maintain the cultural encounters and learning for better mutual understanding.

\section{Conclusion}

No matter what the prevailing external interests are in Indonesia, decentralised democracy in Indonesia highly needs its people. The predominating streams of thought which guide the process of democratisation and decentralisation in the country misjudge the importance and the role of culture. Examining the way in which the transformation has occurred in Indonesia reveals that culture has been perceived more as a burden rather than as a helper in the processes of democratisation and decentralisation. This tendency turns out to be one of the major causes why Indonesia has its progress in decentralization and democratization halted due to its unwillingness to engage in a critical evaluation and honest self-reflection.

Indonesia's ability to make a sufficient response to globalisation requires the completion of the forgotten agenda - establishing Indonesia as a strong nation-state on which cultural diversity serves as its strength, rather than its weakness. Indonesia needs to make sure that it manages to establish a democratic and decentralised political 
structure based on cultural features, although the importance of 77 putting universal values in place does not necessarily imply to disregard local cultures.

Indonesia's ability to do so depends on a double-edged strategy. On the one hand, it needs to reshape the prevailing cultural lens of the public so that it is sensitive in identifying the root causes and superficial causes of social problems. On the other hand, it has to make sure that the reshaped lens equips the members of the public with the capacity to learn from each other and from their past. Beneath the dynamics of the cultural transformation, a silent and salient process of learning should take place. Yet, what we require is not merely the adoption of what has been established elsewhere in other contexts.

There must also be a process of creation and, in some cases, cocreation. Various ideas and aspiration circulated within the discourse and practices of cosmopolitan democracy serve as either common points of reference or as threats to challenge. Willingness to learn allows the creation of capability to make a critical understanding, and allows us to come up with entirely new things that don't necessarily fall under the conflicting dichotomy. While open mindedness is important, this approach will not in anyway have any logical reason to suppose that "we will be able to control the outcomes of our creations and activities". ${ }^{30}$ Mobilising collective capacity to learn is the only hope left, since the norm of interdependence in this globaliaed world requires our willingness to accept the indirect effects of other's activities.*

30 Jim Whitman, The Limits of Global Governance, Routledge, London, 2005, page. 114 . 


\section{Bibliography}

"50 Tahun Kalimantan Tengah", Postgraduate Program for Political Science, Local Politics and Regional Autonomy, 2007.

Anderson, B.R.O.G, 2006, Imagined Communities: Reflection on the Origin and Spread of Nationalism, London: Verso, first published by Verso in 1983

Angle, Stephen C., "Decent Democratic Centralism", Political Theory, Vol. 33 No. 4, August 2005 518-546

Archibugi, Daniele, "Cosmopolitan Democracy and its Critics: A Review”, European Journal of International Relations 2004; 10; 437

Cheema, G. Shabbir, Dennis A. Rondinelli (eds); Decentralizing Governance : Emerging Concepts and Practices, Ash Institute For Democratic Governance And InnovationHarvard University, Washington, 2007.

Chun, Allen, "Globalization as Indigenization, or the "Culture" in Taiwanese National Politics", Journal of Asian and African Studies, 2000; 35; 7

Dhakidae, Daniel (2007) Cendekiawan dan Kekuasaan di Masa Orde Baru, Gramedia: Jakarta.

Failed State Index 2012, The Fund for Peacehttp://www.fundforpeace. org/global/?q=fsi-grid2012, Saturday, June 31, 2012, 11.22pm Fischer, Frank (1990) Technocracy and the Politics of Expertise, Sage Publications: Calif . pp. 15-17.

Held, David,"Globalization, Corporate Practice and Cosmopolitan Social Standards", Contemporary Political Theory, 2002, 1

Jim Whitman, The Limits of Global Governance, Routledge, London, 2005

Kay, Sean; "Globalization, Power, and Security", Security Dialogue Vol. 35, No. 1, March 2004.

Kidwell, Kirk S.; "Politics, Performativity, Autopoiesis: Toward aDiscourse Systems Theory of Political Culture", Studies Critical Methodologies, Volume 9 Number 4, August 2009 533-558.

Lombard, Denys (2000) Nusa Jawa Silang Budaya,Vol 1, 2, 3; Winarsih P.A. et.al transl., P.T. Gramedia Pustaka Utama: Jakarta; first published 1996. 
Martin Leet; "Democracy and the Individual Deliberative and 79 existential Negotiations”; Philosophy \& Social Criticism, vol. 29 no 6, pp. 681-702

May, Peter J., Policy Learning and Failure; Journal of Public Policy part 4, 1992, pp. 331-354.

Nordholt, Henk Schulte and Gerry van Klinken (eds.), 2007, Politik Lokal di Indonesia, Jakarta: KITLV and YOI

Pratikno et.al. (eds.) 2004, Perjuangan Menuju Puncak: Perjuangan Menuju Puncak Kajian Akademis Pembentukan Kabupaten Puncak - Pemekaran Kabupaten Puncak Jaya Provinsi Papua, PLOD UGM and Regency Government of Puncak Jaya Steger, Manfred B.; Globalism: The New Market Ideology, Rowman \& Littlefield Publisher Inc., 2002. 
Cross-cultural Learning for Seceuring Deceentralization ... 